\title{
Improving Geopolymer Characteristics with Addition of Poly-Vinyl Alcohol (PVA) Fibers
}

\author{
Ekaputri, J.J. ${ }^{1}$, Fujiyama, C. ${ }^{2}$, Chijiwa, N. ${ }^{3}$, Ho, T.D. ${ }^{4}$ and Nguyen, H.T. ${ }^{5}$
}

\begin{abstract}
This paper presents the benefits of using Poly-Vynil Alcohol (PVA) fibers in improving the mechanical properties of class $\mathrm{F}$ fly-ash-based geopolymer concrete. The activator was a combination of $8 \mathrm{M}$ sodium hydroxide and sodium silicate. The mass ratio of $\mathrm{Na}_{2} \mathrm{SiO}_{3}$ to $\mathrm{NaOH}$ varied at 1.5, 2,0 and 2.5. Cylindrical specimens with a diameter of $100 \mathrm{~mm}$ and a height of 200 $\mathrm{mm}$ were prepared for compression strength, splitting, and elastic modulus. The PVA fibers in the geopolymers were fixed at $0.4 \%, 0.6 \%$, and $0.8 \%$ by total concrete volume. It was found that the mixture with an alkali ratio of 1.5 and a PVA fiber content of $0.4 \%$ had the best workability. The highest strength was obtained in a mixture with alkali activator ratios of 1.5 with $0.6 \%$ fiber addition. The workability issue and fiber direction in the concrete were the dominant factors influencing the properties of concrete.
\end{abstract}

Keywords: Geopolymer; PVA; fly ash; mechanical properties; alkali ratio.

\section{Introduction}

Geopolymer is a non-Portland cement material that generally uses fly ash as the main binder to produce geopolymer concrete [1,2]. Using fly ash as a choice in making geopolymer technology is one of many inventions to decrease by-product piling in power plants. Geopolymer binder is formed by mixing fly ash with alkali solution, where sodium hydroxide $(\mathrm{NaOH})$ with a concentration of 8 to 16 molar is applied [3,4]. Other than $\mathrm{NaOH}$, sodium silicate $\left(\mathrm{Na}_{2} \mathrm{SiO}_{3}\right)$ is also mixed to enrich soluble silica in the binder system, where the fly ash usually contains less reactive silica than other alumina-silica source e.g. metakaolin. In general, the alkali ratio in the geopolymer concrete mixture is determined by the mass ratio of $\mathrm{Na}_{2} \mathrm{SiO}_{3}$ to $\mathrm{NaOH}$ solution to simplify the mixing design. The ratio is varied from 0.5 to 3.0 depending on the soluble silica requirement in the binder [5]. However, higher alkali ratio cannot be always approved in the mixing. This is because the water to solid ratio becomes low as well as it decreases the fluidity of fresh concrete.

A common mechanical problem with geopolymer concrete is its consistency, which usually is lower than conventional concrete.

\footnotetext{
${ }^{1}$ Civil Engineering Department, ITS, Surabaya, INDONESIA

${ }^{2}$ Department of Urban Innovation, Yokohama National University, JAPAN

${ }^{3}$ Department of Civil Engineering, Tokyo Institute of Technology, JAPAN

${ }^{4,5}$ Department of Electrical Engineering, UiT The Arctic University of Norway

*Corresponding author; Email: januarti@ce.its.ac.id
}

Note: Discussion is expected before July, $1^{\text {st }} 2021$, and will be published in the "Civil Engineering Dimension", volume 23, number 2, September 2021

Received 09 June 2020; revised 16 December 2020; accepted 02 January 2021
Sometimes, micro-cracks occur during the hardening process because of its brittleness and low tensile strength. Proper curing, and the addition of fiber are the solutions to minimize early onset of the occurrence of cracks. Some fibers, such as natural fiber and synthetic fiber, have been recommended as an addition in geopolymer mixture. It has also been reported that a certain fiber composition improved the concrete's mechanical properties [6-15]. Amidst all suggested fibers, poly-vinyl alcohol (PVA) is one of the recommended fibers, since its water absorption is relatively low as well as its excellent tensile property $[11,16]$. It was also discovered that the geopolymer gel covered PVA fiber properly It improves the interfacial bonding strength between the fiber and geopolymer concrete [17]. However, workability problems always occur when the fiber is added in fresh concrete. Therefore, a proper composition is required to determine the optimal mixture composition.

A study on using PVA fiber in geopolymer concrete is presented in this paper. The property of concrete as well as the workability problem of fresh concrete causing the change of geopolymer macro-pore is also provided. Furthermore, this paper also reflects one of the efforts to apply more coal ash to address the problem of waste management at power plants.

\section{Materials and Methods}

\section{Materials}

The main material in this geopolymer mixture is class $\mathrm{F}$ fly ash. The material was obtained from PT Petrokimia Gresik, a fertilizer industry in East Jawa, Indonesia. Its chemical composition by X-Ray Fluorescence $(\mathrm{XRF})$ analysis is listed in Table 1. 
Table 1. Fly Ash Chemical Composition (\% by mass)

\begin{tabular}{ccccccccccc}
\hline $\mathrm{SiO}_{2}$ & $\mathrm{Al}_{2} \mathrm{O}_{3}$ & $\mathrm{Fe}_{2} \mathrm{O}_{3}$ & $\mathrm{CaO}$ & $\mathrm{Na}_{2} \mathrm{O}$ & $\mathrm{K}_{2} \mathrm{O}$ & $\mathrm{TiO}_{2}$ & $\mathrm{MgO}$ & $\mathrm{Mn}_{2} \mathrm{O}_{3}$ & $\mathrm{Cr}_{2} \mathrm{O}_{3}$ & $\mathrm{SO}_{3}$ \\
\hline 48.47 & 26.05 & 12.54 & 5.18 & 0.47 & 1.66 & 0.92 & 2.77 & 0.19 & 0.02 & 1.05 \\
\hline
\end{tabular}

Not all silicate content in Table 1 is reactive. According to a reactivity test, the provided soluble $\mathrm{SiO}_{2}$ was only $33.70 \%$, which is much lower than the total silicate $\left(\mathrm{SiO}_{2}\right)$ provided in Table 1. This means only some particles of silicate in fly ash can react in alkali conditions. The Scanning Electron Microscope (SEM) image of fly ash is presented in Figure 1. It shows some irregular particles that have some potential practical problems because of a rapid setting time. This means the workability of fresh concrete becomes poor because of slump-loss in a very short time.

Since soluble silica plays an important role in the geopolymerization process, $\mathrm{Na}_{2} \mathrm{SiO}_{3}$ gel was added to mix with the $\mathrm{NaOH}$ solution, which was kept constant at 8 molars for all mixtures. $\mathrm{Na}_{2} \mathrm{SiO}_{3}$ consists of $18.5 \% \mathrm{Na}_{2} \mathrm{O}, 36.4 \% \mathrm{SiO}_{2}$, and $45 \% \mathrm{H}_{2} \mathrm{O}$.

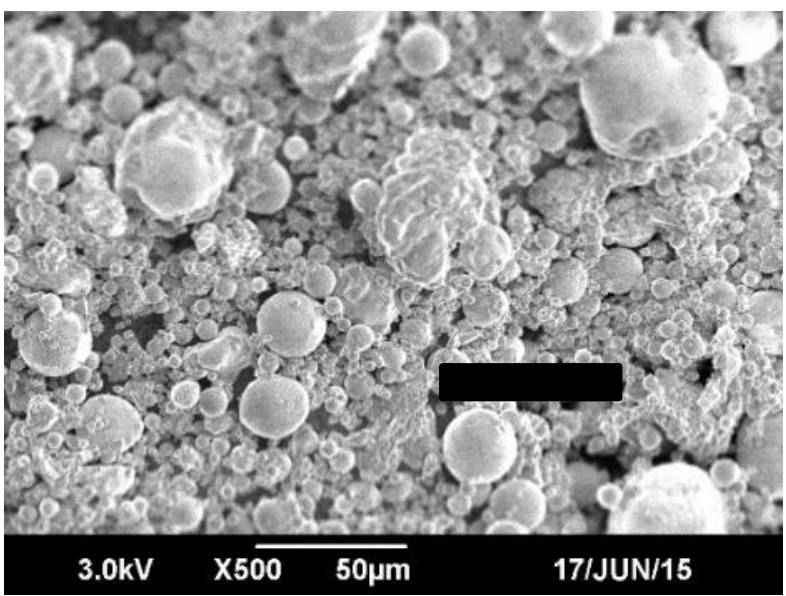

Figure 1. Fly Ash Particles by SEM Image.

Three alkali variations of the $\mathrm{Na}_{2} \mathrm{SiO}_{3}$ to $\mathrm{NaOH}$ ratio were $1.5,2.0$, and 2.5 , that affected the water to solid ratio which varied by $0.27,0.26$, and 0.25 , respectively. The weight ratio of alkali solution to fly ash was kept at 24:74, while the weight ratio of paste (fly ash and alkali) to aggregate was set at 25:75. Locally available aggregates, natural sand and crushed stones were used. To provide proper workability and prevent rapid setting, a polycarboxylate-supperplaticizer was used. It was added to the fresh concrete with a dosage of $2 \%$ of fly ash, by weight. A certain dimension of PVA fiber was selected from NYCONPVA RECS 15. Detailed information is provided in Table 2. The fiber was added at the end of the mixing process to avoid balling of the mixture. In the fresh mixture, variations of fiber by concrete volume were fixed at $0.4 \%, 0.6 \%$, and $0.8 \%$. The mix design of geopolymer concrete and workability of each mixture are presented in Table 3. The code of specimens according to the alkali mass ratio and the fiber content by concrete volume fraction.

Table 2. PVA Fiber Properties

\begin{tabular}{lc}
\hline \multicolumn{2}{c}{ Specification } \\
\hline Diameter (micrometer) & 38 \\
Length $(\mathrm{mm})$ & 8 \\
Tensile $(\mathrm{MPa})$ & 1600 \\
Bending Strength $(\mathrm{MPa})$ & 40000 \\
Melting temperature $\left({ }^{\circ} \mathrm{C}\right)$ & 225 \\
Absorption & $<1 \%$ by mass \\
Density $\left(\mathrm{g} / \mathrm{cm}^{3}\right)$ & 1.3 \\
\hline
\end{tabular}

Fiber application in fresh concrete decreases the workability, and therefore mixtures containing higher fiber content lose slump as shown in Figure 2. Without superplasticizer, the fresh concrete becomes too hard to place in the mould.

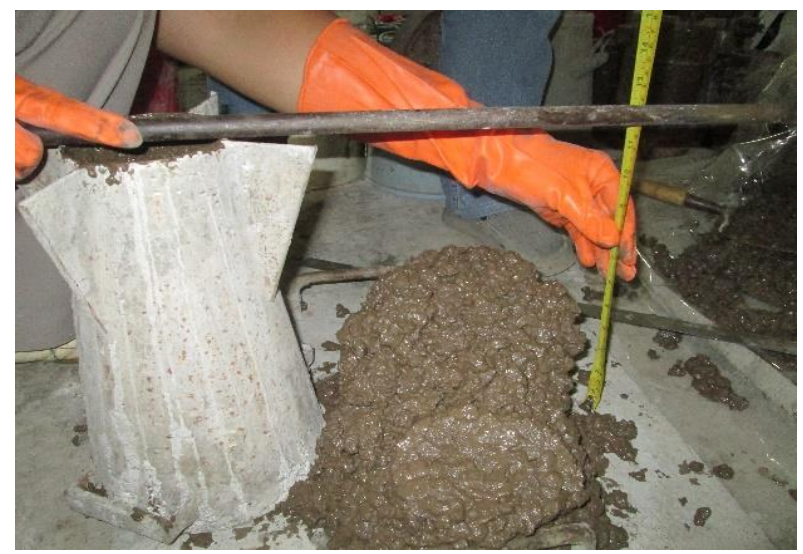

(a) Good workability



(b) Poor workability

Figure 2. Slump Test of Fibrous Mixture 
Table 3. Materials Composition and Workability of Fresh Concrete

\begin{tabular}{|c|c|c|c|c|c|c|c|c|c|c|}
\hline \multirow[b]{2}{*}{ No. } & \multirow[b]{2}{*}{ Code } & \multicolumn{6}{|c|}{$\mathrm{kg}$ per $\mathrm{m}^{3}$} & \multirow[b]{2}{*}{ Alkali ratio } & \multirow{2}{*}{$\begin{array}{c}\text { Fiber } \\
\text { content (\%) }\end{array}$} & \multirow[b]{2}{*}{$\begin{array}{c}\text { Slump } \\
(\mathrm{mm})\end{array}$} \\
\hline & & $\mathrm{NaOH}$ & $\mathrm{Na}_{2} \mathrm{SiO}_{3}$ & Fiber & $\begin{array}{c}\text { Fine } \\
\text { Aggregate }\end{array}$ & $\begin{array}{c}\text { Coarse } \\
\text { Aggregate }\end{array}$ & $\begin{array}{l}\text { Fly } \\
\text { Ash }\end{array}$ & & & \\
\hline 1 & GC1.5-0.4 & 84 & 126 & 4.0 & 720 & 1080 & 390 & 1.5 & 0.4 & 90 \\
\hline 2 & GC1.5-0.6 & 84 & 126 & 6.5 & 720 & 1080 & 390 & 1.5 & 0.6 & 50 \\
\hline 3 & GC1.5-0.8 & 84 & 126 & 10.5 & 720 & 1080 & 390 & 1.5 & 0.8 & 0 \\
\hline 4 & GC2.0-0.4 & 70 & 140 & 4.0 & 720 & 1080 & 390 & 2.0 & 0.4 & 50 \\
\hline 5 & GC2.0-0.6 & 70 & 140 & 6.5 & 720 & 1080 & 390 & 2.0 & 0.6 & 30 \\
\hline 6 & GC2.0-0.8 & 70 & 140 & 10.5 & 720 & 1080 & 390 & 2.0 & 0.8 & 0 \\
\hline 7 & GC2.5-0.4 & 60 & 150 & 4.0 & 720 & 1080 & 390 & 2.5 & 0.4 & 10 \\
\hline 8 & GC2.5-0.6 & 60 & 150 & 6.5 & 720 & 1080 & 390 & 2.5 & 0.6 & 6 \\
\hline 9 & GC2.5-0.8 & 60 & 150 & 10.5 & 720 & 1080 & 390 & 2.5 & 0.8 & 0 \\
\hline
\end{tabular}

Fresh concrete was placed into a cylindrical mould with a diameter of $100 \mathrm{~mm}$ and a height of $200 \mathrm{~mm}$. All specimens were demoulded a day after casting and were cured at moist curing at room temperature until the specific age for testing at 3, 7, 14, 21, and 28 days. A series of testing, according ASTM standards, was conducted. The tests included compressive strength [18], splitting tensile test [19] that is shown in Figure 3, direct tensile test that is shown in Figure 4, modulus of elasticity, Poisson's ratio and porosity. To ensure reliable results, the average of three identical specimens for each variation was reported. Some fiber-free specimens were prepared as a control system.

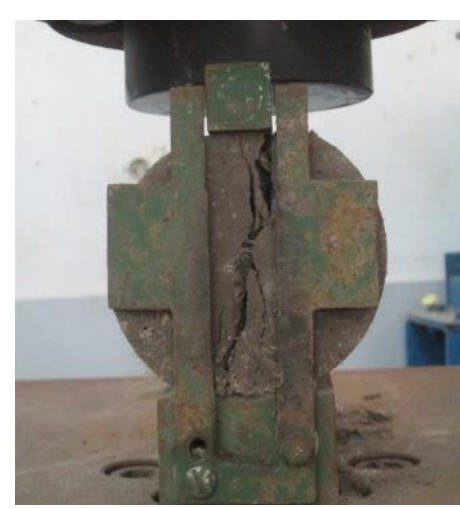

Figure 3. Splitting Test



Figure 4. Direct Tensile Test

\section{Results and Discussion}

\section{Compressive Strength}

The effect of fiber content on compressive strength using different alkali ratios is presented in Figure 5. In general, at the early age, fiber addition shows less influence than at the later age. Because of the interaction between fiber and geopolymer matrices, concrete gained its strength at the later age, caused by the increasing rigidity of the concrete. This occurred when the load was transferred from the matrices to the fiber. However, in the group of specimens with higher alkali ratio (GC2.5), the expected higher strength contributed by the fiber was not found. This is because the fresh concrete in this group already displayed poor workability. The lowest water to solid ratio as the effect of high alkali ratio contributed to this outcome. Therefore, the additional fiber added to the system caused the mixture to be too stiff. Because of the inserted fiber, splitting of concrete matrices took place even at the early age and instigated the lower strength results.

At the later age, the rigidity of the concrete increased because of the interaction between fiber and geopolymer matrices. Concrete gained its strength at the later age of the testing sample. This occurred when the load caused cracks, the fiber restrained the
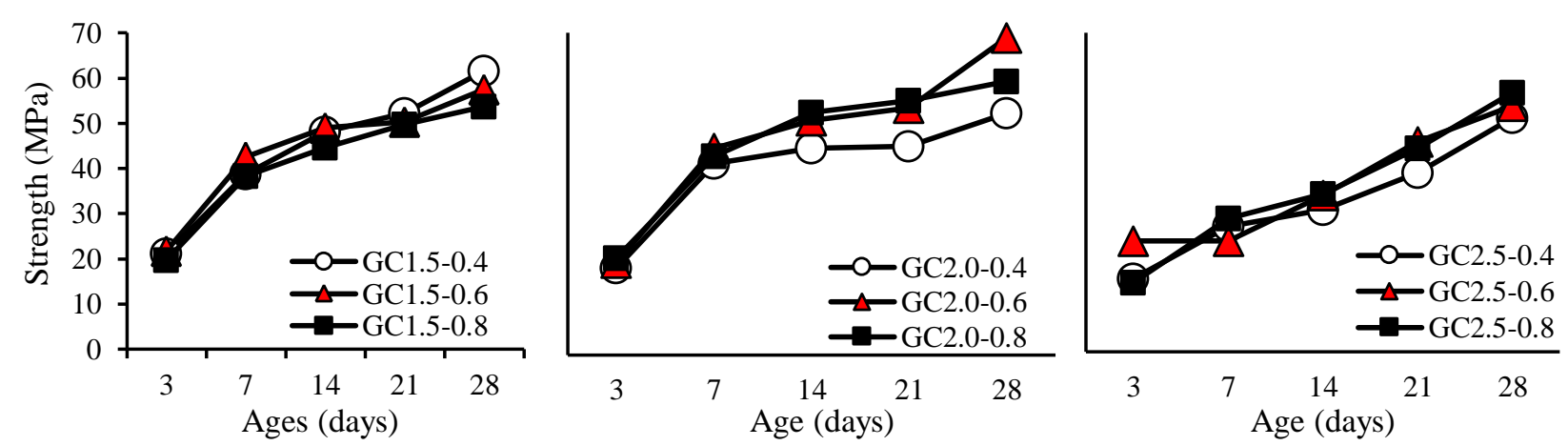

Figure 5. Compressive Strength of Specimens at Different Age 
crack opening. However, with the group of specimens with higher alkali ratio (GC2.5), contribution of fiber to the strength was likely very small. This is because the fresh concrete in this group already had poor workability. The additional fiber added to the system caused the mixture to become rigid. The lowest water to solid ratio as the effect of a higher alkali ratio contributed to this effect. Some disintegration of links between particles and greater formation of internal gap may take place even at the early sample age. It also instigated the lower strength which was observed in this group. This condition is shown in Figure 6, where the contribution of fiber to 28 day-compressive strength is evidently greater at the lower alkali ratio.

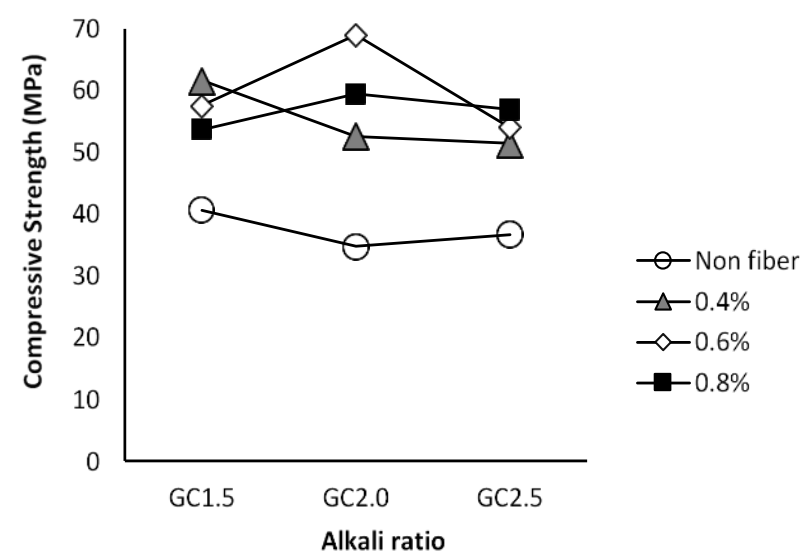

Figure 6. The Effect of Fiber to the Alkali Ratio on Compressive Strength

\section{Splitting Tensile Strength and Direct Tensile Strength}

As predicted, because the fiber's tensile strength is hundreds of times greater than concrete's, its contribution to increase tensile strength of concrete is greater than the compressive strength [20]. Figure 7 shows the effect of fiber to split tensile strength. In a low alkali ratio, mixtures including fiber, demonstrate good strength improvement. In this condition, the fiber contributed to improvements in the splitting strength. This effect occurred where the fiber was distributed evenly in the concrete mixture and showed some resistance to cracks in a direction perpendicular to the fiber, as shown in Figure 8. Fiber has less influence in the specimens with a 2.0 and 2.5 alkali ratio. This was especially seen in the group with an alkali ratio of 2.5 , when the workability of fresh concrete was poor, the effect of $0.8 \%$ fiber by concrete volume on the split strength was very small.

The same phenomenon was observed with the direct tensile test. As the weakness of concrete is its tensile characteristics, almost all the tensile load is restrained by the fiber. However, this occurs when the fiber is distributed evenly in the mixture. In Figure 9, the contribution of fiber to the tensile strength is unseen in the group with alkali ratios of 2.0 and 2.5. Since it is impossible to control the fiber direction in the mixture, because of poor workability, some fibers were positioned in the same direction as the crack's stripe. This is represented in Figure 10. It caused not only a decrease in the tensile strength but also increased the risk of fiber incapacitation to transfer any tensile load.

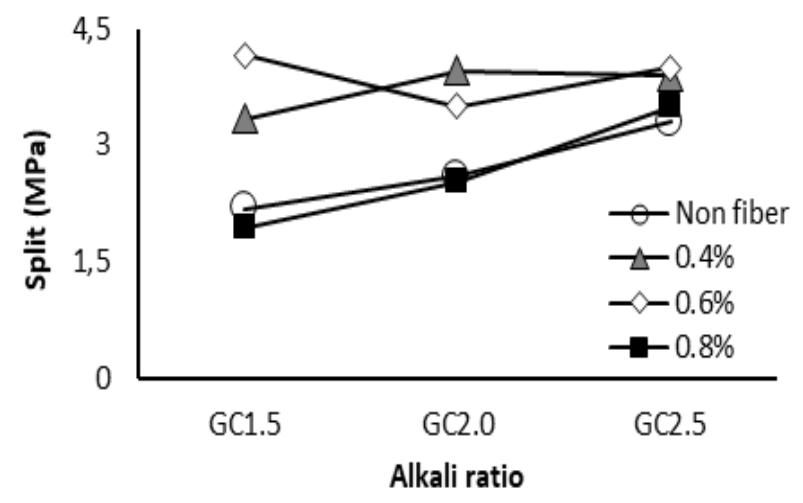

Figure 7. Splitting Tensile Strength



Figure 8. Fiber is Perpendicular to the Crack Direction (750x magnification)

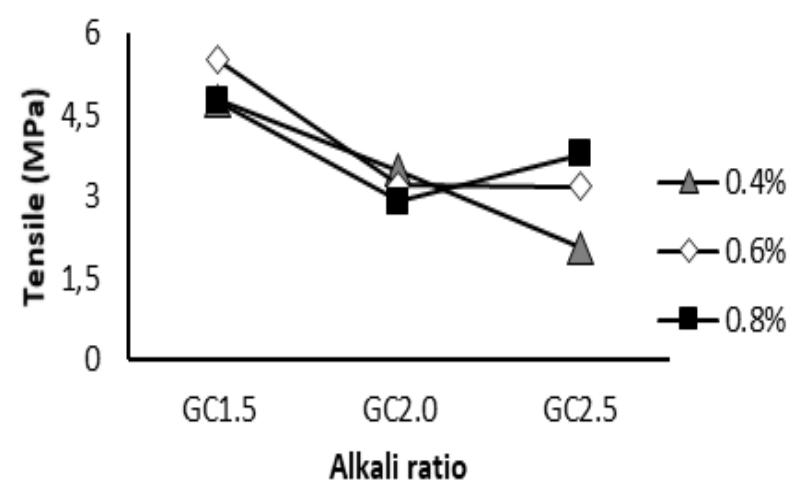

Figure 9. Direct Tensile Test 




Figure 10. Fiber is Alongside the Crack Direction (750x magnification)

\section{Porosity Test}

Compaction of mixture is one of the indicators of concrete quality. Well-compacted concrete during casting produces excellent mechanical properties. A mixture with poor workability causes not only disaggregation of matrices but also macropores which decrease concrete performance.

A series of porosity tests were conducted to investigate the effect of pores on the 28 day-compression strength of concrete. Figure 11 represents the results with dual ordinates: porosity (\%) and 28 daycompressive strength $(\mathrm{MPa})$. Total porosity, which is divided into open and closed porosity, is related to the compaction of the concrete that contributes to its strength. Mixtures with higher porosity resulted in lower strength. Obviously, the presence of fibers increases the potential formation of open porosity that is the main role of total porosity. In every group of alkali ratio, increasing the fiber content to between $0.6 \%$ to $0.8 \%$ by volume fraction caused concrete strength to decrease. However, despite displaying a greater number of pores, the strength of fibrous specimens was always higher than the concrete with no fiber. In Figure 11, the optimum strength is shown by a specimen with alkali ratio of 2 , containing fiber content of $0.6 \%$ by concrete volume.

\section{The Effect of Fiber in Mixture with High Alkali Ratio}

The group of specimens with an alkali ratio of 2.5 was observed to produce some problems with fiber distribution which resulted in low mechanical properties. These specimens were the ones investigated for modulus of elasticity, Poisson's ratio and some mechanical properties of concrete at the sample age of 28 days. The results are presented in Figure 12. Fiber reinforced the concrete and braced the concrete matrices. It acted as a passive-confinement to reduce the Poisson's ratio. Consequently, it enhanced the elastic modulus, compressive and tensile strength. The effect of strength hardening behavior was observed followed by fiber-matrix adhesion. The same phenomenon was found by Trindade et al. [21] and $\mathrm{Xu}$ et al. [22]. However, the direction of fiber was problematic to control during casting. In some cases, where a dense mixture containing more fiber, it resulted in a uniform direction of fiber. This decreases the strength of concrete as the fibers are already localized in the same line with a given load. The load causes the specimens to easily split up. Accordingly, a linear connection between modulus of elasticity and Poisson's ratio and mechanical properties is displayed in Figure 13. This result is slightly different from the previous study [9,11]. In those results, enhancement of all mechanical properties of geopolymer concrete was caused by the application of PVA fiber of up to $0.8 \%$ volume fraction.

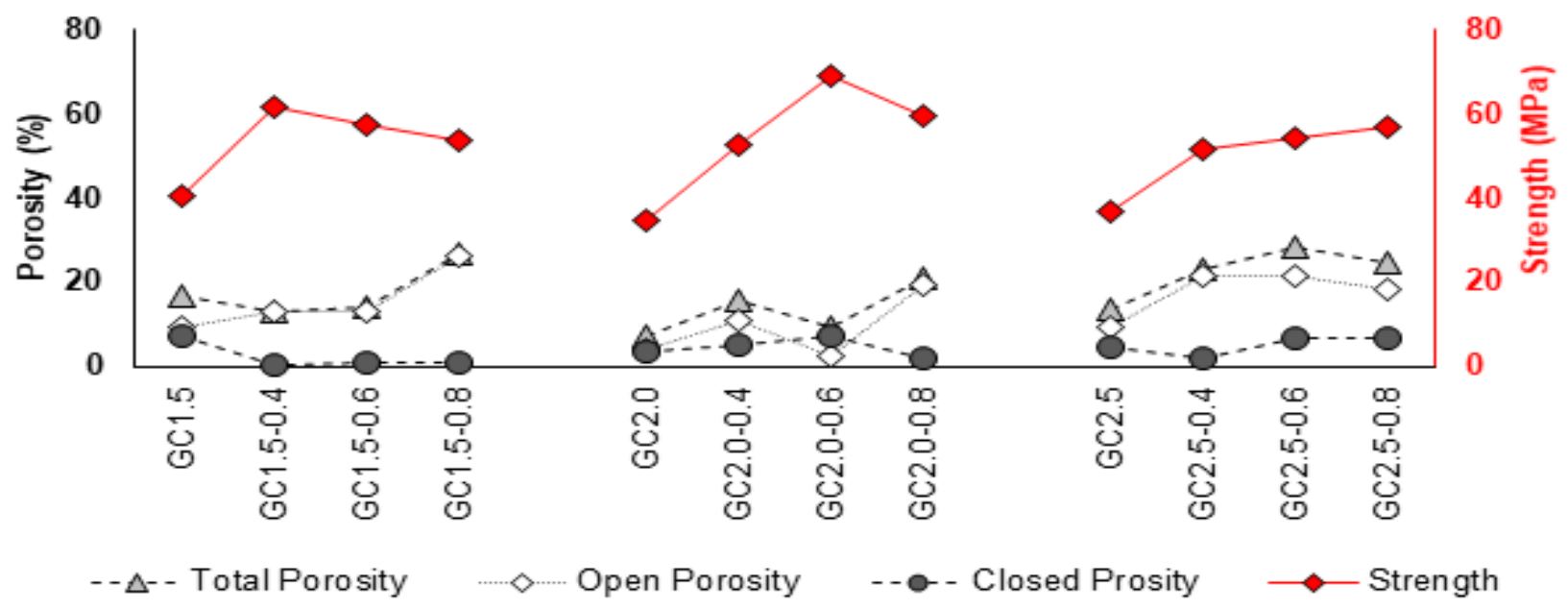

Figure 11. Effect of Porosity on Concrete Strength 



Figure 12. Effect of Fiber on the Mechanical Properties of Concrete
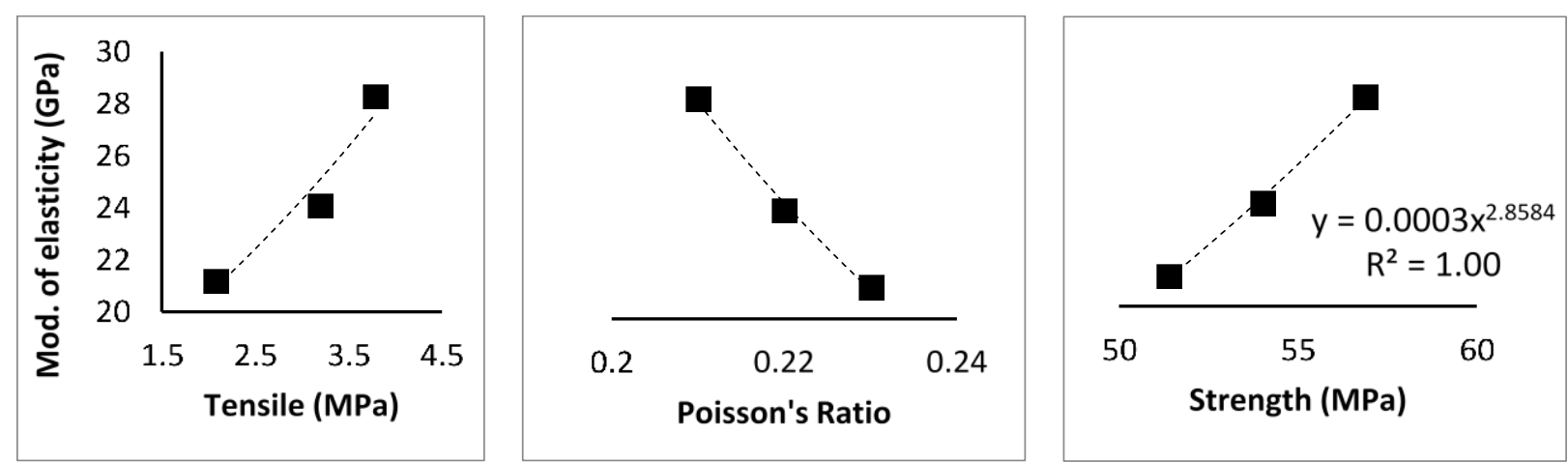

Figure 13. Relation of Elastic Modulus to Concrete Properties

\section{Conclusions}

PVA fiber plays an important role to increase the strength of concrete as it shows a good adhesive property between fiber and matrix. Under compression test, it restrained crack propagation in a perpendicular direction which resulted in compressive strength improvement. Under splitting tensile test and the direct tensile test, the fiber acted as a bridge in the gap of concrete cracks. However, the fiber contribution to compressive strength was developed at the later age. As confirmed through the porosity test, the more concentrated the fiber in the system, especially in dense mixtures, the lower the fiber effect. This disadvantageous result was caused by poor workability as well as inevitable disaggregation of fresh concrete. This can be avoided by applying an appropriate fiber content in the mixture. It is recommended to utilize PVA fiber of up to $0.6 \%$ by concrete volume with the maximum alkali ratio of 2.0.

\section{Acknowledgments}

The authors would like to thank Kasmaji Inti Utama, Co, Ltd., Petrokimia Gresik, Co. Ltd, and Surya Beton Indonesia, Co. Ltd. for providing the materials. The first author was funded by Penelitian Terapan Unggulan Perguruan Tinggi (PTUPT) Grants-in-aid Batch 3, 2020 from the Indonesian Ministry of Research, Technology, and Higher Education.

\section{References}

1. Davidovits, J., Geopolymer Cement for Mitigation of Global Warming, 2014, retrieved from: http://www.geopolymer.org/applications/globalwarming/.

2. Davidovits, J., Geopolymers, Journal of Thermal Analysis, 37(8), 1991, pp.1633-1656.

3. Hardjito, D., Wallah, S.E., Sumajouw, D.M.J., and Rangan, B.V., On the Development of Fly Ash-based Geopolymer Concrete, ACI Materials Journal, 102(6), 2004, pp. 467-472.

4. Hashim, A.N., Kamarudin H., Noorzahan, B., Abdullah, M.M.A.B., Kamrosni, A.R., and Ekaputri, J.J., Effect of Sodium Hydroxide $(\mathrm{NaOH})$ Concentration on Compressive Strength of Alkali-Activated Slag (AAS) Mortars, Applied Mechanics and Materials, 754-755, 2015, pp. 300304.

5. Subaer, Haris, A., Nurhayati, Irhamsyah, A., and Ekaputri, J.J., The Influence of Si:Al and Na:Al on The Physical and Microstructure Characters of Geopolymers based on Metakaolin, Material Science Forum, 841, 2016, pp. 170-177.

6. Abdullah, M.M.A.B., Tahir, M.F.M., Tajudin, M.A.F.M.A., Ekaputri, J.J., Bayuaji, R., and Khatim, N.A.M., Study on the Geopolymer Concrete Properties Reinforced with Hooked Steel Fiber, IOP Conference Series: Materials Science and Engineering, 2017. 
7. Araújo, D.L., Danin, A.R., Melo, M.B., and Rodrigues, P.F., Influence of Steel Fibers on the Reinforcement Bond of Straight Steel Bars, IBRACON Structures and Materials Journal, 6(2), 2013, pp. 307-338.

8. Behnood, A. and Ghandehari, M., Comparison of Compressive and Splitting Tensile Strength of High-Strength Concrete with and without Polypropylene Fibers Heated to High Temperatures, Fire Safety Journal, 44(8), 2009, pp. 1015-1022.

9. Ekaputri, J.J., Junaedi, S., and Wijaya, Y.P., Effect of Curing Temperature and Fiber on Metakaolin-based Geopolymer, SCESCM 2016, Bali, Indonesia, Procedia Engineering, 2017.

10. Harajli, M.H., Hout, M., and Jalkh, W., Local Bond Stress-Slip Behavior of Reinforcing Bars Embedded in Plain and Fiber Concrete, $A C I$ Materials Journal, 92(4), 1995, pp. 343-353.

11. Manfaluthy, M.L. and Ekaputri, J.J., The Application of PVA Fiber to Improve the Mechanical Properties of Geopolymer Concrete, EACEF 2017, MATEC Web of Conferences, Seoul, 2017.

12. Nematollahi, B., Sanjayan, J., Qiu, J., and Yang, E.H., High Ductile Behavior of A Polyethylene Fiber-Reinforced One-Part Geopolymer Composite: A Micromechanics-based Investigation, Archives of Civil and Mechanical Engineering, 17(3), 2017, pp. 555-563.

13. Nematollahi, B., Sanjayan, J., and Shaikh, F.U.A., Comparative Deflection Hardening Behavior of Short Fiber Reinforced Geopolymer Composites, Construction and Building Materials, 70, 2014, pp. 54-64.

14. Ohno, M. and Li, V.C., A Feasibility Study of Strain Hardening Fiber Reinforced Fly AshBased Geopolymer Composites, Construction and Building Materials, 57, 2014, pp. 163-168.
15. Tekle, B.H., Khennane, A., and Kayali, O., Bond Properties of Glass Fibre Reinforced Polymer Bars with Fly-Ash Based Geopolymer Concrete, $10^{\text {th }}$ International Conference on Composite Science and Technology, 10, Lisbon, Portugal, September 2015.

16. Tanyildizi, H. and Yonar, Y., Mechanical Properties of Geopolymer Concrete Containing Polyvinyl Alcohol Fiber Exposed to High Temperature, Construction and Building Materials, 126, 2016, pp. 381-387.

17. Xu, F., Deng, X., Peng, C., Zhu, J., and Chen, J., Mix Design and Flexural Toughness of PVA Fiber Reinforced Fly Ash-Geopolymer Composites, Construction and Building Materials, 150, 2017, pp. 179-189.

18. American Standard Testing Methods C 39, Standard Test Method for Compressive Strength of Cylindrical Concrete Specimens, ASTM International, 2003.

19. American Standard Testing Methods C 496M, Standard Test Method for Splitting Tensile Strength of Cylindrical Concrete Specimens, ASTM International, 2011.

20. Ekaputri, J.J., Limantono, H., and Triwulan, Effect of PVA Fiber in Increasing Mechanical Strength on Paste Containing Glass Powder, Key Engineering Materials, 673, 2016, pp. 83-93.

21. Trindade, A.C.C., Borges, P.H.R., and Silva, F.A., Mechanical Behavior of Strain-Hardening Geopolymer Composites Reinforced with Natural and PVA Fibers, Materials Today: Proceedings, the $4^{\text {th }}$ Brazilian Conference on Composite Materials, 8, 2019, pp. 753-759.

22. Xu, S., Malik, M.A., Qi, Z., Huang, B.T., Li, Q., and Sarkar, M., Influence of the PVA Fibers and $\mathrm{SiO}_{2} \mathrm{NPs}$ on the Structural Properties of Fly Ash based Sustainable Geopolymer, Construction and Building Materials, 164, 2018, pp. 238-245. 